\title{
The process of natural succession in urban areas
}

Wayne C. Zipperer

\section{Introduction}

Succession has been a fundamental concept in ecology. Its classical definition is the onderly change in vegetation at a site that is predictable and directional towards a climax state or end point (Clements 1916). A general assumption of succession is that early seres are governed by allogenic processes, environmental processes external to the site, and early seres facilitate later successional stages. As the community matures, autogenic processes, biotic interactions, become important in facilitating later-successional assemblages and the movement of the community towards an end point (Connell and Slatyer 1977). Field studies often showed trajectories were not always predictable, end points were not always achieved, and allogenic processes played an important role in community dynamics throughout successional development. To shift the focus of successional studies away from descriptive to mechanisms or interactions that contribute to successional change, Connell and Slatyer (1977) proposed three distinct mechanisms-facilitation, tolerance, and inhibition-at the community level.This shift enabled experimental approaches to studying succession, but it failed to capture the complexity of vegetation dynamics (Pickett et al. 1987a).

Clements (1916) lists five basic causes of succession: (1) a disturbance opening a site; (2) migration of propagules to the site; (3) establishment of species; (4) biotic interactions; and (5) modification of the site by organisms. Pickett et al. (1987a, 1987b) synthesized this list into a single-organized framework that captures vegetation dynamics at multiple scales. At the highest level of hierarchical organization, three general and universal conditions exist: (1) site availability; (2) differential species availability; and (3) differential species performance (Figure 16.1) (Pickett et al. 1987b). At the next lower or intermediate level, an individual mechanism or causation is defined for each condition as, for example, the availability of species depends on dispersal and propagule pools. This level in turn can be examined further for a particular process.

Most successional studies have been conducted in non-urban landscapes. Although these studies can provide a framework to study succession in an urban landscape, they do not capture the uniqueness of the urban matrix (see Rebele 1994). In this chapter, I will use the hierarchy of causes of vegetation dynamics - site availability, differential species availability, and differential species performance-to examine factors and mechanisms influencing succession in urban landscapes and overview some examples of successional studies in cities. 


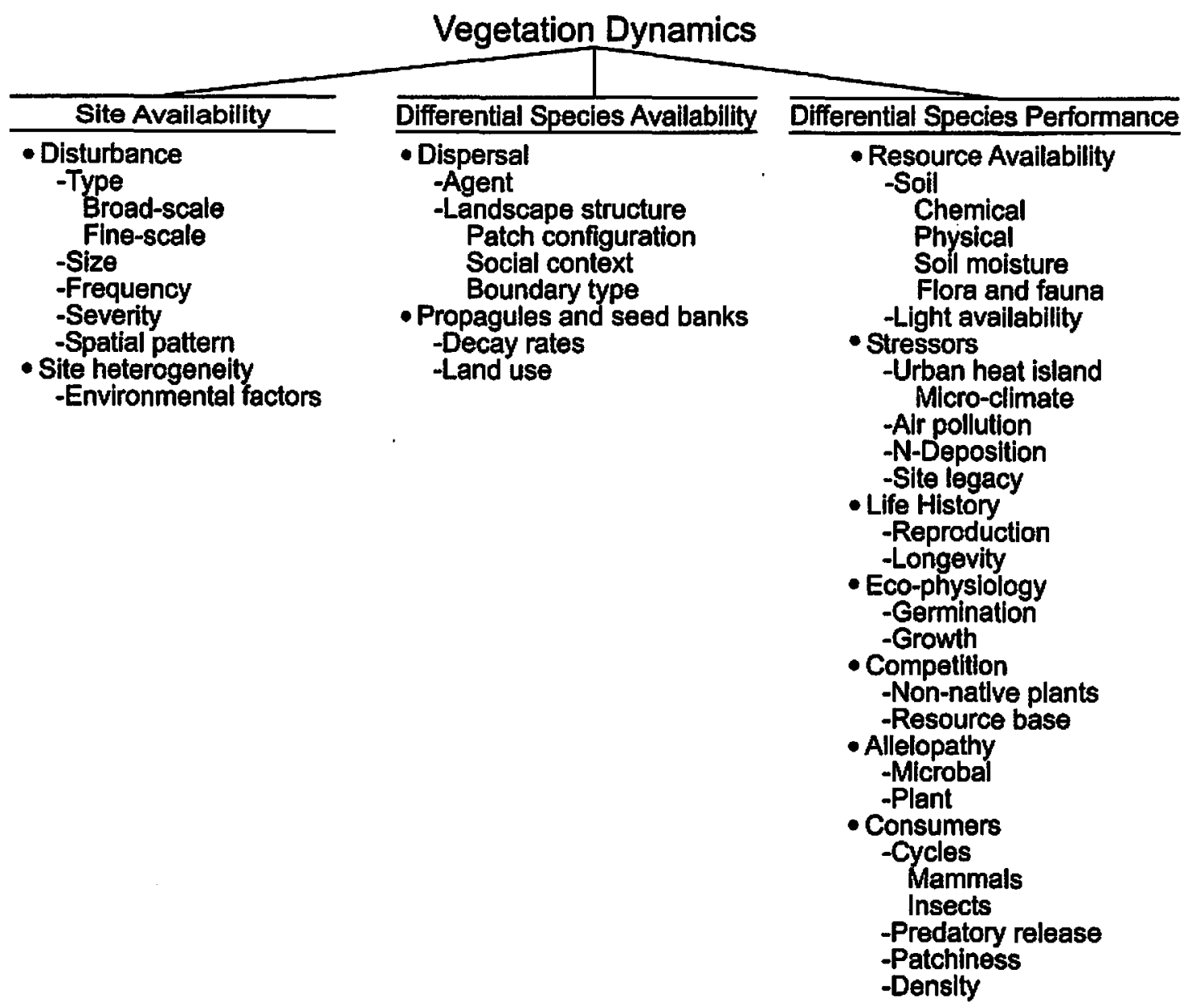

Figure 16.1 Vegetation dynamics is illustrated as a hierarchy ranging from the most general phenomenon of community change to detailed interactions within a mechanism or causation. Adapted from Pickett et al. (1987b) and Pickett and Cadenasso (2005).

\section{Site availability}

Site availability includes not only sites created by disturbances (broad scale) (Pickett and White 1985), but also the death of an individual and existing site conditions (fine scale) (Brand and Parker 1995). A disturbance is defined as "any discrete event in time that disrupts [landscape], ecosystem, community, or population structure and changes resources, substrate availability, or physical environment" (Pickett and White 1985). Natural disturbances that affect urban landscapes include wind and ice storms, fire, and flooding as well as herbivory (e.g. insect outbreaks), pathogens, and stress-induced mortality. A disturbance can be classified by its seasonality, distribution, frequency, magnitude, and severity (Pickett and White 1985) and, collectively, all of the disturbances affecting a landscape are called the disturbance regime.

The primary site disturbance in the urban landscape is land clearing for development. Site clearing can range from an area less than 0.25 hectare for a single structure, thus possibly leaving the adjacent vegetation relatively intact, to clearing the entire area for an entire subdivision (e.g. $>50 \mathrm{ha}$ ). Site clearing can include not only removing existing vegetation cover but also removing soil and possibly altering drainage patterns (Effland and Pouyat 1997). Such extensive clearing can 
create a new substrate as A and B horizons of the soil profile are removed. Successional processes on these sites would be defined as primary succession rather than secondary succession since this new substrate has not previously supported vegetation, does not contain a seed bank, and possibly has not accumulated organic matter. In general, primary succession is associated with glaciated and volcanic sites rather than urban sites. In the urban landscape, primary succession is associated with stone and brick walls, demolition sites, spoil heaps from industrial waste, and abandoned roads and sidewalks (Rebele 1992,1994). Contrary to vegetation dynamics in adjacent rural areas where secondary succession dominates, both primary and secondary successional processes are important ecological processes in urban landscapes.

The disturbance regime changes as a landscape is urbanized. Some disturbances such as fires and flooding are suppressed because of their devastating effects on property and the potential for loss of life. For instance, fire suppression reduces the frequency and alters the intensity of fire events. A subsequent outcome is a shift away from fire-dependent species to more mesic species and new plant communities. In the Chicago Metropolitan area, fire suppression has changed the oak savannah from a community dominated by Quercus spp. and grasses to one containing Acer saccharum and exotic species (Kline 1997).

Similarly, humans introduce new disturbances. Sharpe et al. (1986) observed an increase in frequency of fire because of arson, trampling, dumping of yard and garden waste, and vandalism in urban woodlands in the Milwaukee metropolitan area. A study of reforested vacant lots in Syracuse, New York revealed that 80 percent of sites sampled were disturbed intensively and extensively by human activities such as vandalism, fire, trampling, and dumping (Zipperer 2002). Matlack (1993) called this human effect a sociological-edge effect because most human activities occurred within $82 \mathrm{~m}$ of the edge.

Even though these novel disturbances create new sites for colonization, they affect the germination and growth of species. For instance, trampling is a novel, small-scale, frequent disturbance which many native species have not evolved mechanisms to cope with. Without natural barriers such as high stones and down-woody debris to created micro-safe sites, trees did not regenerate in remnant forest in Helsinki, Finland because of trampling (Lehvävirta et al. 2004).

Management activities can also be considered a type of disturbance. The type, frequency, and intensity of management will significantly influence vegetation dynamics (Zipperer et al. 1997). For instance, if a vacant lot is regularly managed by mowing, its structure and composition would differ from a vacant lot that is left unmanaged (sensu Godefroid and Koedam 2007). Overall, site management activities, such as mowing, clearing, and weeding, inhibit or alter successional processes.

Brand and Parker (1995) recognized that seasonality, environmental heterogeneity within the site, and environmental factors of the site can influence germination and growth. Environmental factors particularly important to urban landscapes include urban heat island, atmospheric pollution (e.g. nitrogen deposition and ozone), altered soil properties (physical and chemical), soil moisture, and light availability (Rebele 1994; Pickett et al. 2001) (see species performance section for more detail).

Another aspect of site condition is its landscape structure and social context. Landscape structure refers to site location in an urban landscape with respect to adjacent land uses as well as site configuration (e.g. shape, size, and orientation). Both attributes have been shown to influence site composition (see Godefroid and Koedam 2003). Social context refers to the social attributes of the site and adjacent sites. A study of plant diversity in Phoenix, Arizona, a city in the Sonoran desert of the United States, showed that in addition to elevation, former land use, home owner income and housing age were significant site attributes influencing vegetation dynamics (Hope et al. 2006). 


\section{Differential species availability}

Differential species availability depends on the species' ability either to survive the disturbance, vegetative or in the seed bank, or disperse to the site (Pickett and Cadenasso 2005). In an urban landscape, species pool includes native and non-native species (Kühn et al. 2004). Rather than overview the quite extensive plant dispersal and seed bank literature (e.g. Leck et al. 1989; Poschlod et al. 2005), I will focus on three human-mediated dispersal (HMD) mechanisms-(1) vehicle, (2) horticultural stock, and (3) footwear-that augment natural dispersal in urban landscapes (Wichmann et al. 2009).

\section{Vehicles}

The importance of vehicles as dispersal vectors has been recognized for some time (e.g. Ridley 1930), but it has been only recently that they have been intensively studied. In Sheffield, England, Hodkinson and Thompson (1997) collected mud in the fall and summer from wheel-wells of parked vehicles. They observed that small seeds were commonly found in the mud and their densities varied seasonally. The most frequent occurring species included Plantago major (29.2 percent), Poa annua (16.5 percent), Poa trivialis (10.5 percent), Urtica dioica (6.4 percent), and Matricaria discoidea (5.6 percent). To quantify deposition and the movement of seeds into and out of a city, von der Lippe and Kowarik $(2007,2008)$ initiated a series of studies using seed traps in traffic tunnels leading into and out of Berlin. The studies showed that egress traffic was transporting, to a greater extent, more non-native species into the peri-urban than ingress traffic was transporting native species into the city. Consequently, sites within the urban core would be colonized locally by non-native species, whereas peri-urban sites could be colonized by native and non-native species occurring locally as well as those non-native species being transported by cars.

\section{Horticultural stock}

There are two aspects of horticultural stock that influence species availability-(1) the actual species being planted, and (2) contamination of the horticultural stock with non-native seeds or plants. Although a number of invasive, non-native species were introduced because of agricultural or forestry practices during the nineteenth and early twentieth centuries, horticultural or ornamental materials are becoming the primary sources for invasive species in the urban landscape (Reichard and White 2001). These introductions often expand the native range of the species and facilitate expansion of the species as new sites become locally available (Kowarik 2003). Without these introductions and secondary expansions, many of the invasive species would not have expanded their natural range as quickly as observed (Pyšek and Hulme 2005).

The contamination of plotted soil can be thought of as a subset of a much broader category of topsoil, which may contain seeds that have been removed from one site and transported to another (Hodkinson and Thompson 1997). By planting contaminated plots or augmenting existing soil with imported topsoil, new species can be added to a site where they otherwise may not have occurred.

\section{Footwear}

Although footwear can be a dispersal agent for any habitat visited by humans, I have included it here because of the density of footwear in urban areas and the movement of people from 
private to public lands and from urban to rural areas. Footwear serves as a secondary dispersal mechanism. Seeds, which are picked up by footwear, have the potential to be carried farther than if dispersed by natural means only. Wichmann et al. (2009) observed for two species of Brassica that the maximum distance of dispersal by wind was $250 \mathrm{~m}$, whereas dispersal distances by footwear exceeded $5 \mathrm{~km}$.

\section{Urban landscape}

In the previous section, social context and landscape position were identified as important site factors. Similarly, the urban landscape, itself, affects species availability. For instance, the size of the city will determine the number of available native and non-native species. Larger cities will have more non-native species, whereas smaller communities and villages have a higher proportion of native species (Pyšek 1998). Similarly, Williams et al. (2009) report that the urban landscape serves as a filtering mechanism through habitat transformation, fragmentation, urban environmental conditions, and human preferences. These filters work synergistically to influence floristic composition. Habitat transformation and fragmentation remove or alter existing habitat patches, thus eliminating species or drastically reducing their density. The urban environment, as previously discussed and will be discussed in greater detail in the section, creates a unique environment to which many species have not adapted, thus they are not able to survive or compete. Human preference is a socio-economic filter that captures human preferences for specific phenotypic characteristics, thus many new species (i.e. non-native species) are introduced into the urban landscape that otherwise would not have occurred (Williams et al. 2009).

\section{Differential species performance}

Once a species has colonized a site, its performance depends on its interactions with abiotic and biotic conditions (Pickett and Cadenasso 2005) (Figure 16.1). Unfortunately, auteological studies of native and non-native species in urban landscapes are lacking. Rather than focusing on how an individual species may perform within the urban matrix, I will overview those factorssoils, physical stressors, and consumers - that have unique attributes in the urban landscape and significantly affect species performance.

\section{Soils}

Soil factors influencing species performance include higher soil temperature due to the urban heat island effect; lower soil moisture due to soil hydrophobicity; higher concentrations of heavy metals due to emissions; and greater nitrogen and calcium deposition also due to emissions (White and McDonnell 1988; McDonnell et al. 1997; Lovett et al. 2000). In addition, the biotic environment also has been altered. When compared to rural woodlands, urban woodlands had lower densities of soil micro-invertebrates and fungi (Pouyat et al. 1994) but a higher density of earthworms (Steinberg et al. 1997) (see also Chapter 15 this volume). Nitrogen studies of rural and urban woodland soils have indicated that soils in urban woodlands have a substantial amount of extractable soil nitrate and nitrify rapidly (Pouyat et al. 1996; Carreiro et al. 1999). Vallet et al. (2008) observed also that soil $\mathrm{pH}$ and nitrogen content were important indicators of species occurrence in remnant forest patches along urban-to-rural gradients in Angers and Rennes, France.

When overlaying the disturbance regime of a site, anthropogenic inputs and materials, environmental factors, and atmospheric deposition, a mosaic of soil patches occur across the 
urban landscape that range from highly disturbed in industrial wastelands to relatively undisturbed conditions in remnant forest patches. A comparison of soil attributes across this matrix reveals significant differences for bulk density, $\mathrm{pH}$, and concentrations of potassium, phosphorus, sodium and aluminum (Pouyat et al. 2007). Bulk density was the discerning variable between forest and other land uses, whereas soil $\mathrm{pH}$ differentiated residential land use from other non-forested land uses.

\section{Physical stressors}

The primary physical stressors in the urban landscape are the urban-heat island, elevated carbon dioxide $\left(\mathrm{CO}_{2}\right)$, and atmospheric pollution. It is important to note that these stressors do not act independently of each other but rather synergistically. Likewise, their effects can vary across urban landscape because of the spatial heterogeneity within that landscape.

The urban heat island is an important anthropogenic climate modification because of its effect on biological processes. It is the temperature differential between the rural and urban landscape (often the urban core) at dusk. This differential can be as great as $12^{\circ} \mathrm{C}$ depending on the size of the city and its morphology (Oke 1973 and Chapter 11 this volume). In general, larger cities have a greater temperature differential from adjacent rural landscape than smaller cities and towns. When one considers the potential additive effect of the projected increases in mean global temperatures by 1.7 to $4.9^{\circ} \mathrm{C}$ from global climate change with the urban-heat island effect, the additional heat loading on species will significantly affect ecosystem structure and function (Carreiro and Tripler 2005).

In addition to temperature, urban landscapes have elevated $\mathrm{CO}_{2}$ concentrations because of fossil fuel consumption, a phenomenon called urban $\mathrm{CO}_{2}$ dome (Idso et al. 2002). In Phoenix, Arizona, Idso et al. (2002) observed that the urban core and surrounding suburban landscape had a 67 percent and a 33 percent increase, respectively, in $\mathrm{CO}_{2}$ concentration over the value $(370 \mathrm{ppmV}$ ) observed for the rural landscape. From a species performance perspective, the increase in $\mathrm{CO}_{2}$ coupled with the increase in temperature from the urban heat island effect has a significant effect on species productivity. Ziska et al. (2004) observed an increase in plant height, biomass and seedling number for Chenopodium album, a native forb species in the United States, in urban sites when compared to rural sites. Similar enhanced-growth patterns have been observed for non-native forb species, and this urban effect may be one of the possible factors leading to their invasiveness (Ziska 2003).

This increase in productivity is further augmented by nitrogen deposition, wet and dry in the urban landscape. Lovett et al. (2000) observed that $\mathrm{N}$ inputs for urban-remnant forests in New York City were 17 times greater than found in rural remnant forests. Analysis of throughfall over the course of the growing season for remnant forest in Louisville, Kentucky showed that $\mathrm{N}$ deposition was 33 percent greater than rural remnant forest (Carreiro and Tripler 2005). Nitrophilous species have been identified as a primary functional group occupying early successional sites (Godefroid 2001).

Urban areas also have high concentrations of many gaseous, particulate, and photochemical pollutants including $\mathrm{NO}_{x}, \mathrm{HNO}_{3}, \mathrm{SO}_{x}, \mathrm{H}_{2} \mathrm{SO}_{4}, \mathrm{O}_{3}$ and volatile organic compounds (Lovett $e t$ al. 2000; Gregg et al. 2003). $\mathrm{O}_{3}$ may be detrimental to plant growth (Krupa et al. 1998); however, the effect of $\mathrm{O}_{3}$ on growth may be offset by warmer temperatures from the urban heat island effect and higher concentrations of nitrogen and $\mathrm{CO}_{2}$ (Ziska 2003). The synergetic effect of these physical stressors on a species performance needs to be a focus of future research if we are to gain a better understanding of vegetation dynamics for different site conditions. 


\section{Herbivory}

Published studies examining the effect of wildlife populations on regeneration on urban sites are limited. Parker and Nilon (2008) have observed squirrel densities in urban areas exceeding 33 individuals per hectare. At these high densities, intensive seed predation by squirrels can eliminate opportunities for regeneration. In fact, high squirrel densities have been attributed to the poor regeneration of oaks in urban woodlands in New York City (Sisinni and Emmerich 1995).

Likewise, the number of species and density of insectivores may be reduced in urban landscapes because of habitat fragmentation and loss. For instance, Christie and Hochuli (2005) observed a decline in insectivorous birds and an increase in insect herbivory in small remnant forest patches when compared to edge sites and large forest remnant patches. Similarly, a species, whose vigor is already reduced because of the urban environment, may be more susceptible to insect attacks. In Gainesville, Florida, southern pine beetle (Dendroctonus frontalis), a native insect, attacked loblolly pines weakened by an extended drought (www.interfacesouth.org/products/pdf/case_studies 1 . pdf). The outbreak moved from the city into the surrounding areas. The mechanisms driving herbivory (e.g. predator release) in the urban landscape are complex and the diversity of responses by plant species to the synergistic effect of the urban environment and herbivory needs to be studied in more detail (Christie and Hochuli 2005).

\section{Plant traits}

In general, the urban environment tends to select for specific plant traits. For waste lands or vacant lots, these traits include a tolerance for nitrogenous conditions; soils that are dry, rocky, alkaline, and fertile; shade intolerance, and small seeds (Pyšek et al. 1995, 2004; Godefroid and Koedam 2007; Thompson and McCarthy 2008). Although these traits may provide insights into what species may be present, they do not provide insights into how a species will respond to the urban environment. More long-term monitoring of plant communities across a range of habitats need to be conducted for urban landscapes to successfully identify mechanisms and species responses that influence vegetation dynamics.

\section{Succession in the urban landscape}

A limited number of successional studies have focused on the urban landscape and these studies have principally examined the vacant/wasteland lots within European cities (see Rebele 1992; Pyšek et al. 2004; Rebele 2008). In general, successional pathways on vacant lots followed those observed for abandoned fallow lands in rural landscapes. Prach and Pyšek (2001) observed after 12 years native woody species dominating ruderal-urban sites in the Czech Republic. On nutrient poor sites, Populus tremula dominated, whereas on moderately rich nutrients sites Sambucus nigra and Salix caprea dominated. Similarly, site conditions rather than seasonality were observed to be important conditions for different successional pathways (Rebele 2008). In Berlin-Dahlem, Germany, Rebele (1992) tested three substrates-commercial topsoil, ruderal (landfill) soil, and sand-to assess vegetation dynamics over a five year period. On the topsoil, annuals gave way to biennials and perennials. On the ruderal soil, Solidago canadensis dominated the site after the first year. On sandy soils, Betula pendula and Populus nigra colonized the plot after five years. By comparison, sites that were continuously disturbed tended to remain being dominated by ruderal species (Pyšek et al. 2004).

Successional studies in rural landscapes, however, may not always be applicable to vegetation dynamics in urban landscapes. For instance, a comparative study of native grasslands in southeastern 
Australia and South Africa showed that vegetation dynamics in remnant patches of grasslands along roads and railways in rural landscapes differed from remnant grasslands in urban landscapes (Cilliers et al. 2008). In rural landscapes, non-native species occurrence was principally an edge effect, whereas in the urban landscape occurrence resulted from both edge effect and gap-phase dynamics in the interior portion of the grasslands. Predicting vegetation dynamics based on the rural grassland remnants would not have identified the patterns of occurrence in the interior of grassland in urban landscapes.

For remnant forest patches, vegetation dynamics have been documented by comparing current vegetation with historical records rather than following permanent plots through time (e.g. Rudnicky and McDonnell 1989; Godefroid 2001). Rudnicky and McDonnell (1989) reported for a virgin forest stand in the Bronx Botanical Garden, New York, that composition shifted from slow growing Quercus spp. to fast growing Betula and Prunus spp. and structure shifted from larger diameter to smaller diameter trees. These shifts were attributed to increases in seed predation, loss of regeneration from trampling by visitors, and changes in the structure of the forest floor.

\section{Conclusion}

Vegetation dynamics in urban landscapes differ from those in rural landscapes. Both primary and secondary successional processes are important processes in urban landscapes as opposed to adjacent rural landscapes. Likewise, the availability of species shift from rural to urban. In urban landscapes non-native species play a significant role in vegetation dynamics especially in vacant/ wasteland sites and there is a decline in native species richness (Kühn et al. 2004; McKinney 2006). Finally, the urban environment and land transformation create unique environmental conditions that species must adapt to in order to survive and mature.

The loss of native species and the increase in non-native species as a landscape becomes more urbanized have lead to the concept of biotic homogenization-the same "urban-adaptable" species becoming increasingly widespread and locally abundant in urban areas (McKinney 2006). Likewise, a comparison of species similarity across plant communities in urban and rural landscapes showed that urban communities were more similar in composition than the rural communities (McKinney 2006). Even though species composition is becoming more homogenous, the combination of native and non-native species creates novel communities that have not been documented before (Hobbs et al. 2006). These emergent communities create new niches and the opportunity for evolutionary development. How these combinations influence vegetation dynamics as well as ecosystem structure and function have yet to be determined.

\section{References}

Brand,T. and Parker,V.T. (1995) Scale and general laws of vegetation dynamics, Oikos, 73(3): 375-80.

Carreiro, M.M., Howe, K., Parkhurst, D.F., and R.V. Pouyat (1999) Variation in quality and decomposability of red oak leaf litter along an urban-rural gradient, Biology and Fertility of Soils, 30(3): 258-68.

Carreiro, M.M. and Tripler, C.E. (2005) Forest remnants along urban-rural gradients: Examining their potential for global climate research, Ecosystems, 8(5): 568-82.

Christie, FJ. and Hochuli, D.F. (2005) Elevated levels of herbivory in urban landscapes: Are declines in tree health more than an edge effect? Ecology and Society, 10(2): 1-10.

Cilliers, S.S., Williams, N.S.G., and Barnard, FJ. (2008) Patterns of exotic plant invasions in fragmented urban rural grasslands across continents, Landscape Ecology, 23(10): 1243-56.

Clements, F.E. (1916) Plant Succession:An Analysis of the Development of Vegetation, Washington, D.C.: Carnegie Institute, Publication 242.

Connell, J.H. and Slatyer, R.O. (1977) Mechanism of succession in natural communities and their role in community stability and organization, American Naturalist, 111(982): 1119-44. 
Effland, W.R. and Pouyat, R.V. (1997) The genesis, classification, and mapping of soils in urban areas, Urban Ecosystems, 1(4): 217-28.

Godefroid, S. (2001) Temporal analysis of the Brussels flora as indicator for changing environmental quality, Landscape and Uiban Planning, 52(4): 203-24.

Godefroid, S. and Koedam, N. (2003) How important are large vs. small forest remnants for the conservation of the woodland flora in an urban context? Global Ecology and Biogeography, 12(4): 287-98.

Godefroid, S. and Koedam, N. (2007) Urban plant species patterns are highly driven by density and function of built-up areas, Landscape Ecology, 22(8): 1227-39.

Gregg. J.W., Jones, C.G., and Dawson, T.E. (2003) Urbanization effects on tree growth in the vicinity of New York City, Nature, 424: 183-7.

Hobbs, R.J., Arico, S., Aronson, J., Baron, J.S., Bridgewater, P., Cramer, V.A., Epstein, P.R., Ewel, J.J., Klink, C.A., Lugo, A.E., Norton, D., Ojima, D., Richardson, D.M., Sanderson, E.W., Valladares, F., Vila, M., Regino, Z., and Zobel, M. (2006) Novel ecosystems: theoretical and management aspects of the new ecological world order, Global Ecology and Biogeography, 15:1-7.

Hodkinson, D.J. and Thompson, K. (1997) Plant dispersal: the role of man, Journal of Applied Ecology, 34(6): 1484-1496.

Hope, D., Gries, C., Casagrande, D., Redman, C.L., Grimm, N.B., and Martin, C. (2006) Drivers of spatial variation in plant diversity across the central Arizona-Phoenix ecosystem, Society and Natural Resources, 19(2): 101-16.

Idso, S.B., Idso, C.D., and Balling Jr., R.C. (2002) Seasonal and diurnal variations of near-surface atmospheric $\mathrm{CO}_{2}$ concentration within a residential sector of the urban $\mathrm{CO}_{2}$ dome of Phoenix, AZ USA, Atmospheric Environment, 36(10): 1655-60.

Kline, V.M. (1997) Orchards of oak and a sea of grass, in S. Packard and C.F. Mutel (eds.), The Tallgrass Restoration Handbook, Washington, D.C.: Island Press, pp. 3-20.

Kowarik, 1. (2003) Human agency in biological invasions: secondary releases foster naturalisation and population expansion of alien plant species, Biological Invasion, 5(4): 293-312.

Krupa, S.V., Tonneijck, A.E.G., and Maning, W.J. (1998) Ozone, in R.B. Flagler (ed.), Recognition of Air Pollution Injury to Vegetation, Pittsburgh, PA: Air and Waste Management Association, pp. 2.1-2.28.

Kühn, I., Brandl, R., and Klotz, S. (2004) The flora of German cities is naturally species rich, Evolutionary Ecology Research, 6: 749-64.

Leck, M.A., Parker,V.T., and Simpson, R.L. (eds.) (1989) Ecology of Seed Banks, San Diego, CA:Academic Press.

Lehvävirta, S., Rita, H., and Koivula, M. (2004) Barriers against wear affect the spatial distribution of tree saplings in urban woodlands, Urban Forestry and Urban Greening, 3(1): 3-17.

Lovett, G.M., Traynor, M.M., Pouyat, R.V., Zhu,W., and Baxter, J.W. (2000) Atmospheric deposition to oak forests along an urban-rural gradient, Environmental Science and Teclinology, 34(20): 4294-300.

Matlack, G.R. (1993) Sociological edge effects: spatial distribution of human impact in suburban forest fragments, Environmental Management, 17(6): 829-35.

McDonnell, M.J., Pickett, S.T.A., Groffman, P., Bohlen, P., Pouyat, R.V., Zipperer, W.C., Parmelee, R.W., and Medley, K. (1997) Ecosystem processes along an urban-to-rural gradient, Urban Ecosystems, 1(1): 21-36.

McKinney, M.L. (2006) Urbanization as a major cause of biotic homogenization, Biological Conservation, 127(3): 247-60.

Oke, T.R. (1973) City size and the urban heat island, Atmospheric Environment, 7(8): 769-79.

Parker, T.S. and C.H. Nilon (2008) Gray squirrel density, habitat suitability, and behavior in urban parks, Urban Ecosystems, 11(3): 243-55.

Pickett, S.T.A. and Cadenasso, M.L. (2005) Vegetation dynamics, in E. van der Maarel (ed.), Vegetation Ecology, Malden: Blackwell Science, pp. 172-98.

Pickett, S.T.A. and White, P.S. (eds.) (1985) The Ecology of Natural Disturbance and Patch Dynamics, New York: Academic Press.

Pickett, S.T.A., Collins, S.C., and Armesto J.J. (1987a) A hierarchical consideration of causes and mechanisms of succession, Vegetatio, 69(1-3): 109-14.

Pickett, S.T.A., Collins, S.C., and Armesto J.J. (1987b) Models, mechanisms and pathways of succession, Botanical Review, 53(3): 335-71.

Pickett, S.T.A., Cadenasso, M.L., Grove, J.M., Nilon, C.H., Pouyat, P.V., Zipperer W.C., and Costanza, R. (2001) Urban ecological systems: linking terrestrial ecological, physical, and socioeconomic components of metropolitan areas, Annual Review of Ecology and Systematics, 32: 127-57. 
Poschlod, P., Tackenberg O., and Bonn, S. (2005) Plant dispersal potential and its relationship to species frequency and co-existence, in E. van der Maarel (ed.), Vegetation Ecology, Malden: Blackwell Science, Pp. 147-71.

Pouyat, P.V., McDonnell, M.J., and Pickett, S.T.A. (1996) Litter and nitrogen dynamics in oak stands along an urban-rural gradient, Urban Ecosystems, 1(2): 117-31.

Pouyat, R.V., Parmelee, R.W., and Carreiro, M.M. (1994) Environmental effects of forest soil-invertebrate and fungal densities in oak stands along an urban-rural land use gradient, Pedobiologia, 38: 385-99.

Pouyat, R.V., Yesilonis, I.D., Russell-Anelli, J., and Neerchal, N.K. (2007) Soil chemical and physical properties that differentiate urban land-use and cover types, Journal of the Soil Science Society of America, 71(3): 1010-19.

Prach, K. and P. Pyšek (2001) Using spontaneous succession for restoration of human-disturbed habitats: Experience from central Europe, Ecological Engineering, 17(1): 55-62.

Pyšek, P. (1998) Alien and native species in central European urban floras: a quantitative comparison, Journal of Biogeography, 25(1): 155-63.

Pyšek, P. and Hulme, P.E. (2005) Spatio-temporal dynamics of plant invasions: Linking pattern to process, Ecoscience, 12(3): 302-15.

Pyšek, P., Prach, K., and Šmilauer, P. (1995) Relating invasion success to plant traits:An analysis of the Czech alien flora, in P. Pyšek, K. Prach, M. Rejmánek and M. Wade (eds.), Plant Invasions-General Aspects and Special Problems, Amsterdam: Academic Publishing, pp. 39-60.

Pyšek, P., Chocholoušková, Z., Pyšek, A., Jorošik, V., Chytrý, M., and Tichý, L. (2004) Trends in species diversity and composition of urban vegetation over three decades, Journal of Vegetation Science, 15(6): 781-8.

Rebele, F. (1992) Colonization and early succession on anthropogenic soils, Jourmal of Vegetation Science, 3(2): 201-8.

Rebele, F (1994) Urban ecology and special features of the urban ecosystem, Global Ecology and Biogeography Letters, 4(6): 173-87.

Rebele, F. (2008) Vegetation development on deposit soils starting at different seasons, Plant Ecology, 195(1): 1-12.

Reichard, S.H. and White, P.S. (2001) Horticulture as a pathway of invasive plant introductions in the United States, BioScience, 51(2): 103-13.

Ridley, H.N. (1930) The Dispersal of Plants Throughout the World, Ashford: Reeve \& Co.

Rudnicky. J.L. and McDonnell, M.J. (1989) Forty-eight years of canopy change in a hardwood-hemlock forest in New York City, Bulletin of the Torrey Botanical Club, 116(1): 52-64.

Sharpe, D.M., Stearns, F, Leitner, L.A., and J.R. Dorney, L.A. (1986) Fate of natural vegetation during urban development of rural landscapes in southeastern Wisconsin, Urban Ecology, 9(3-4): 267-87.

Sisinni, S.M. and Emmerich,A. (1995) Methodologies, results and applications of natural resource assessment in New York City, Natural Areas Joumal, 15: 175-88.

Steinberg, D.A., Pouyat, R.V., Parmelee, R.W., and Groffman, P.M. (1997) Earthworm abundance and nitrogen mineralization rates along an urban-rural land use gradient, Soil Biology and Biochemistry, 29(3-4): 427-30.

Thompson, K. and M.A. McCarthy (2008) Traits of British alien and native urban plants, Joumal of Ecology, 96(5): 853-9.

Vallet, J., Daniel, H., Beaujouan,V., and Rozé, E. (2008) Plant species response to urbanization: comparison of isolated woodland patches in two cities of North-Western France, Landscape Ecology, 23(10): 1205-17.

von der Lippe, M. and Kowarik, I. (2007) Long-distance dispersal of plants by vehicles as a driver of plant invasions, Conservation Biology, 21(4): 986-96.

von der Lippe, M. and Kowarik, I. (2008) Do cities export diversity? Traffic as dispersal vector across urban-rural gradients, Diversity and Distribution, 14(1): 18-25.

White, C.S. and McDonnell, M.J. (1988) Nitrogen cycling processes and soil characteristics in an urban versus rural forest, Biogeochemistry, 5(2): 243-62.

Wichmann, M.C., Alexander, M.J., Soons, M.B., Galsworthy, S., Dunne, L., Gould, R., Fairfax, C., Niggemann, M., Hails, R.S., and Bullock, J.M. (2009) Human-mediated dispersal of seeds over long distance, Proceedings of the Royal Society B, 276(1656): 523-32.

Williams, N.S.G., Schwartz, M.W.,Vesk, P.A., McCarthy, M.A., Hahns, A.K., Clemants, S.E., Corlett, R.T., Duncan, R.P., Norton, B.A., Thompson, K., and McDonnell, M.J. (2009) A conceptual framework for predicting the effect of urban environments on floras, Journal of Ecology, 97(1): 4-9. 
Zipperer, W.C. (2002) Species composition and structure of regenerated and remnant forest patches within an urban landscape, Urban Ecosystems, 6(4): 271-90.

Zipperer, W.C., Foresman, T.W., Sisinni, S.M., and Pouyat, R.V. (1997) Urban tree cover: an ecological perspective, Urban Ecosystems, 1(4): 229-46.

Ziska, L.H. (2003) Evaluation of the growth responses of six invasive species to past, present, and future atmospheric carbon dioxide, Journal of Experimental Biology, 54(381): 395-404.

Ziska, L.H.,J.A. Bounce, R.V., and Goins, E.W. (2004) Characterization of an urban-rural $\mathrm{CO}_{2}$ /temperature gradient and associated changes in initial plant productivity during secondary succession, Community Ecology, 139(3): 454-58. 


\section{The Routledge Handbook of Urban Ecology}

Edited by lan Douglas, David Goode, Mike Houck and Rusong Wang
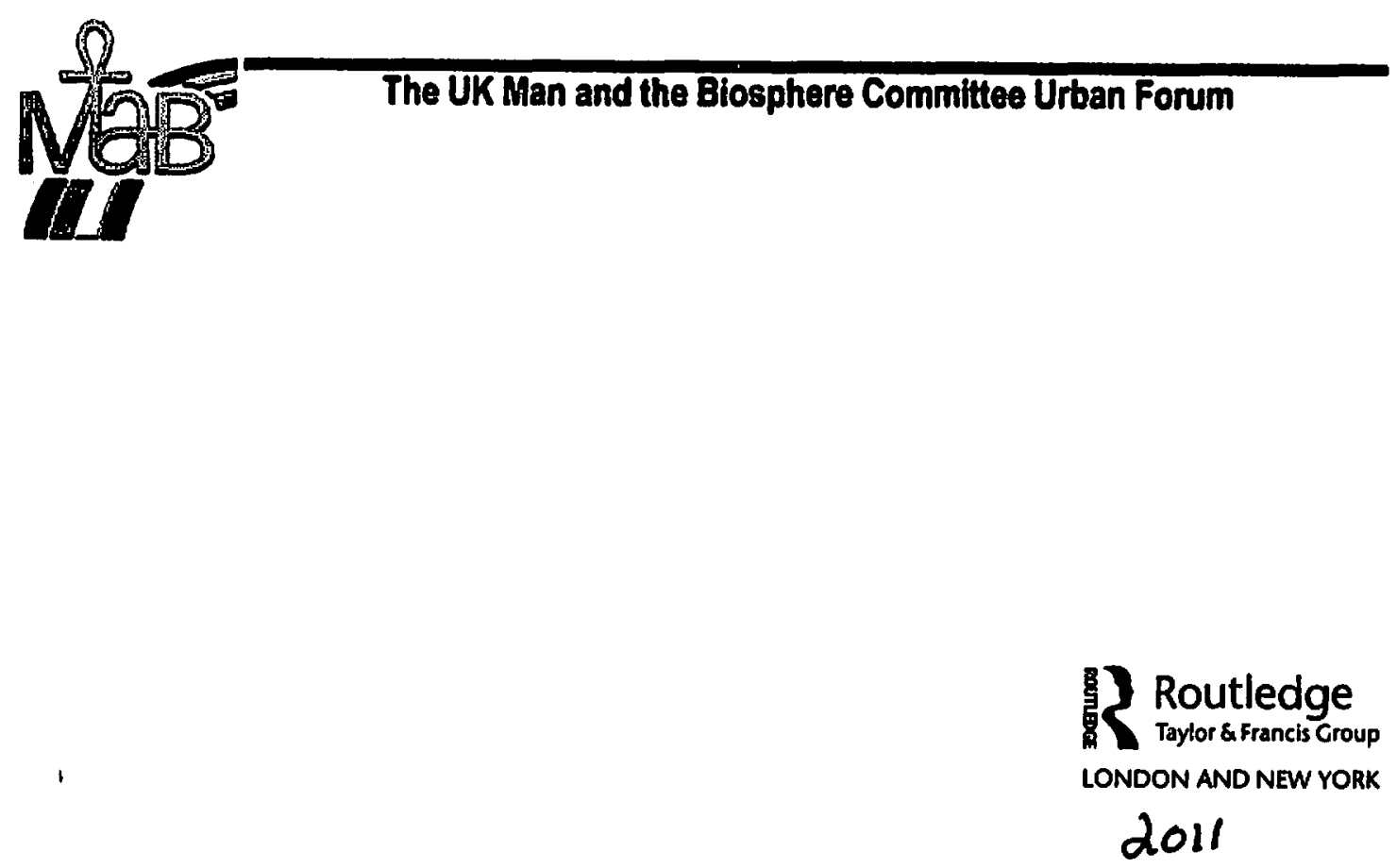